\title{
Synthesis of type A Zeolite membrane: Application for retention of heavy metals
}

\author{
NajibTijani, Khalid Yamni, SaidLamsiah and AbdelhadiEl Krouk \\ Departement of Chemistry, Equipe Matériaux, Membranes et Procédés de Séparation \\ University Moulay Ismail, Faculty of Sciences, Meknes, Morocco
}

\begin{abstract}
The zeolites are the porous materials having a large number of cavities. The existence of these cavities creates a large internal surface. They are classified into different categories, depending on their pore size. The size of pores allows the classification of zeolites. We distinguish the microporous, macroporous and Mesoporousmaterials. The aims of this study are to synthetize a type A zeolite. the characterization was carried out by X-ray diffraction of powder. The determination of the true cell is widely discussed.One of the most applications of zeolite is the retention of some ions in the solution. The present work discusses the ability of our zeolite to capture the heavy ions. So to follow this, a measure of concentrations of solutions is made before and after filtration.
\end{abstract}

Keywords: Zeolite, X-ray diffraction, clay, heavy ions, filtration

\section{Introduction}

In the last few decades, significant progress has been witnessed of about zeolites supported membranes, due to their potential application in separation and catalysis process [1-5]. Synthesis concepts such as secondary growth on seeded support were developed and for more than 20 years, zeolite membranes, especially $\mathrm{NaA}$ zeolite membranes have been intensively investigated in wide range of applications due to their uniform pore structure and high thermal stability.

In order to study the pollution from industrial effluents by eliminating some very toxic heavy metals $(\mathrm{Cd}, \mathrm{Pb}$, Co), membrane filtration method is adopted. A thin layer of type A zeolite was deposited on the clay substrates [6-7].The membrane is developed to provide a technical solution to the problems generated by the discharge in different receiving environments. Theprocesses used, in general, are microfiltration, ultrafiltration and Nanofiltration[8]. The adjustment of the surface properties of different membranes to optimize flow and rejection stability rate during filtration must be realized in first time[9-13]

\section{Synthesis}

\section{Experimental}

The synthesis[8] procedure is divided into two stages:

- $\quad$ Preparation of the precursors of aluminate and silicate in $\mathrm{NaOH}$ solution.

- $\quad$ Mixture of the precursors previously prepared.

In a polyethylene flask containing water, add $0.15 \mathrm{~mol}$ of sodium hydroxide, let stirring until a homogeneous solution is obtained.After complete dissolution and cooling, add 0.02 molof sodium aluminate and let stirring for 10 minutes. The solution becomes completely transparent. Put at $50^{\circ} \mathrm{C}$ for 12 hours in a sealed container. Similarly, the same preparation is made for the sodium silicate ( $\mathrm{Na} 2 \mathrm{Si} 3 \mathrm{O} 7,27 \% \mathrm{SiO} 2,17 \% \mathrm{NaOH}$ ).

The precursor solution of zeolite is synthetized from the mixture of the two solutions prepared above. This mixture is stirring after the addition of aluminate precursor solution on the silicate precursor. Once this step is completed, the mixture was stirred for 30 minutes.

After mixing, the autoclave is put at $\mathrm{T}=80^{\circ} \mathrm{C}$ for at least 24 hours. The solid produced isseparated by vacuum filtration and washed with distilled water until the $\mathrm{pH}$ value is close to 9 . Then the sample was dried at $\mathrm{T}=$ $100^{\circ} \mathrm{C}$ for 24 hours.

\section{Characterization of the zeolite sample by $\mathrm{X}$-ray diffraction}

$\mathrm{X}$-ray powder diffraction data were collected with a 6100 Shimadzu diffractometer using $\mathrm{CuK}$ radiation and a monochromator. The measured 2 theta range $\left(5-90^{\circ}\right)$ was scanned in steps of $0.02^{\circ}$ with a counting time of $3 \mathrm{~s} / \mathrm{step}$. This 2 theta range was used for the refinement of cell parameter. The aperture and the soller slits were set at $1.0^{\circ}$.

The geometry is the $\square-2 \square$. The sample is ground. The figure 1 shows the X-ray spectrumobtained. 


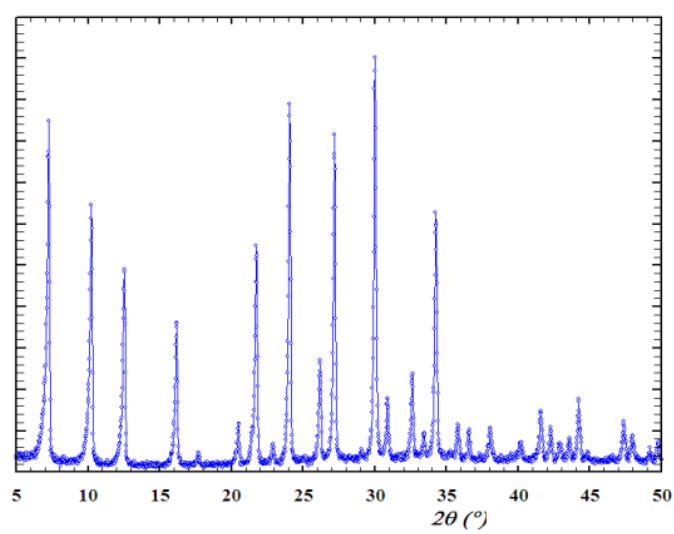

Figure 1: X-ray spectrum of synthetized zeolite

The table 1 below summarizes the results obtained by the 3 software used for decomposition and indexation.

Table 1: Parameters of cells and space group for the synthesized zeolite

\begin{tabular}{|c|c|c|c|c|c|c|c|}
\hline & $\mathbf{a}$ & $\mathbf{b}$ & $\mathbf{c}$ & $\square$ & $\square$ & $\square$ & Space group \\
\hline DICVOL & 12.2938 & 12.2938 & 12.2938 & 90 & 90 & 90 & Pm-3m \\
\hline TREOR & 12.2749 & 12.2749 & 12.2749 & 90 & 90 & 90 & Pm-3m \\
& 12.2747 & 12.2747 & 12.2747 & 90 & 90 & 90 & \\
\hline NTREOR & 12.2769 & 12.2769 & 12.2769 & 90 & 90 & 90 & Pm-3m \\
\hline
\end{tabular}

The results show that the cell is cubic with parameter $a=12.28 \AA$ approximately. In order to search the true cell and the best group we have used the CheckCell program[14]. We are unable to index all reflexions with the parameter $\mathrm{a}=12.28 \AA$.

The presence of reflexion at $2 \square=21.53^{\circ}$ not indexed by the cell found letus think that the parameter of cell is double. With this change, we can indexthe entire spectrum. The best space group is immediately found. In our case the space group is $\mathrm{F} \mathrm{m}-3 \mathrm{c}$.

The Fullprof program[15] involves lebail procedure to optimize cell parameter, peak profiles, integrated Bragg intensities, and background coefficients. These parameters are refined in order to minimize the coefficients of reliability used to measure the similarity between the simulated and experimental powder patterns. The space group found $\mathrm{F} \mathrm{m}-3 \mathrm{c}$ fits all reflections. In our case the newly refined parameter of cell is $a=24.5732 \AA$. The figure 2 shows the result obtained by profile matching.

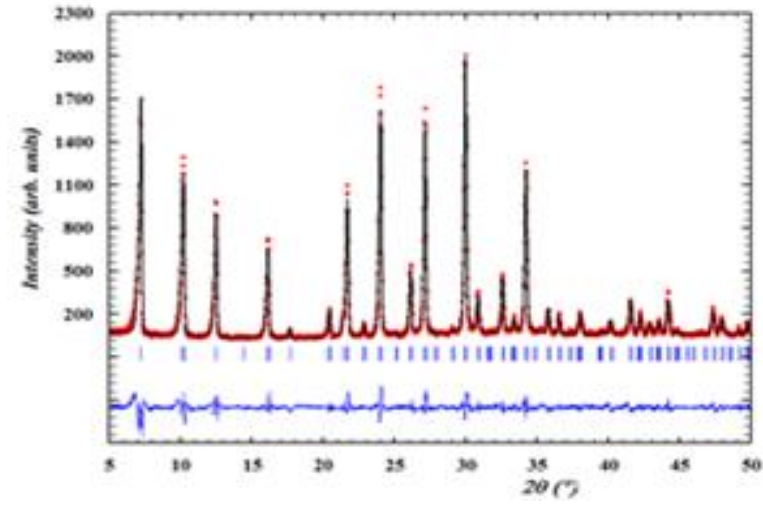

Figure 2:Profile matching applied on zeolite $\mathrm{x}$-ray spectra

\section{Preparation and characterization of macro-porous support}

The clay used in this work comes from the region of Meknes (South East $4 \mathrm{~km}$ ). The sieved powder used alone (AS) or with adjuvants such as activated carbon (AC) or starch AA for the development of media plan [16]. The raw materials (AS) are prepared by sintering according to the results obtained with the TGA and DTA analyzes.

The figure 3 shows the image of surface obtained from microscopy realized on the elaborated support. 


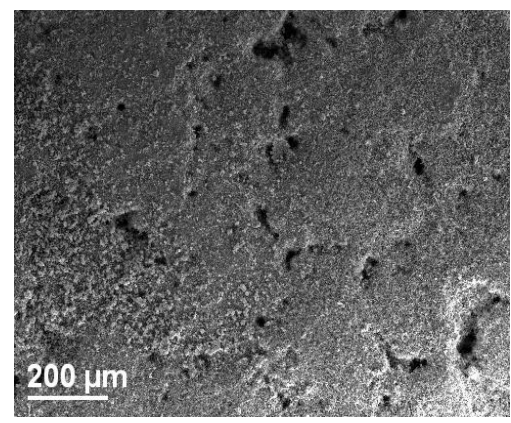

Figure 3: Micrograph of the clay support

\section{Deposition of zeolite}

After the development and characterization of materials based on clay, a zeolite deposit was made by the hydrothermal method using the following protocol:

- Preparation of the precursors of silicates and aluminates,

- Mixture of the two precursors,

- Introduction of the carrier in the mixture,

- putting in the oven at various temperatures $\left(\mathrm{T}=40^{\circ} \mathrm{C}, 50^{\circ} \mathrm{C}\right.$ and $\left.60^{\circ} \mathrm{C}\right)$ for $24 \mathrm{~h}$.

The ScaningEectronic Microscopy (figure 4) shows that the synthesis at $60^{\circ} \mathrm{C}$ for $24 \mathrm{~h}$ in an oven gives a deposit with a uniform structural morphology of zeolite type A

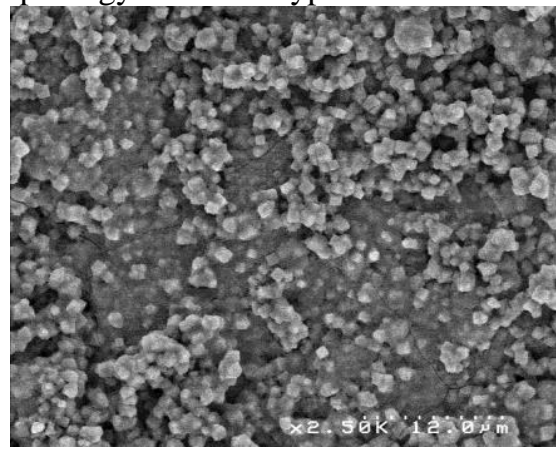

Figure 4: Micrograph of zeolite type A

\section{Study of filtration}

After the preparation of our membrane (support with zeolite), we realized a filtration on pilot in order to obtain information about the retention of heavy metals. At first, one must characterize the membrane by flow study. The figure 5 shows the filtration pilot used for the retention of heavy metals in the solution.

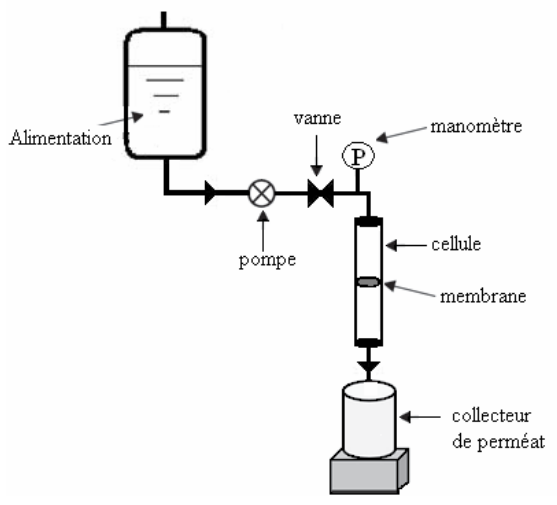

Figure 5: Pilot cross flow

The ultra-pure water is used having a resistivity of $18 \mathrm{M} \Omega$. After, we prepared the solutions containing heavy metals ions such as: $\mathrm{Cd} 2+, \mathrm{Pb} 2+$ and $\mathrm{Co} 2+$ at concentrations greater than $50 \mathrm{mg} / \mathrm{L}$.

We have followed the retention at different times. The table 2 summarizes the results obtained after this experience. The concentrations of ions were determined by inductively coupled plasma spectrometry (ICPAES). 
Synthesis of type A Zeolite membrane: Application for retention of heavy metals

Table 2: Concentrations obtained by ICP of heavy metals before and after filtration

\begin{tabular}{|c|c|c|c|c|c|}
\hline $\begin{array}{l}\text { Concentrations } \\
\mathrm{mg} / \mathrm{L}\end{array}$ & $\mathrm{t}=\mathbf{0} \mathrm{mn}$ & $\mathrm{t}=30 \mathrm{mn}$ & $t=1 h$ & $\mathrm{t}=1 \mathrm{~h} 30$ & $t=2 h$ \\
\hline Cd2+ & 147.01 & 0.08 & 0.06 & 0.05 & 0.05 \\
\hline Pb2+ & 307.51 & 29.82 & 12.02 & 0.94 & 0.31 \\
\hline Co2+ & 55.46 & 3.98 & 2.59 & 1.63 & 1.23 \\
\hline
\end{tabular}

\section{Conclusion}

In this work, we have prepared and characterized by XRD the zeolite type A. The NaA zeolite crystallizes in space group $\mathrm{F}$ m-3c with parameter of lattice $\mathrm{a}=24.5732 \AA$. The refinement of this parameter was made by profile matching in Fullprof software. The zeolite was deposed on the clay support in order to manufacture a membrane. The SEM shows that membrane is continuous and uniform. The studies of the retention of heavy metals were carried out by pilot filtration. The percentage of retention is about $98 \%$ after $2 \mathrm{~h}$. We can note that the retention time of cadmium is thelower. NaAZeolite membranes show promising properties for heavy metals removal in effluents liquids. The mechanism ofions retention by various types of Zeolite membrane is under study.

\section{References}

[1] J. Coronas, J. Santamaria, Separations using zeolite membranes, Sep.Purif. Meth.28, (1999), 127.

[2] T. Bein, Synthesis and applications of molecular sieve layers and membranes, Chem. Mater. 8 (1996) 1636

[3] A. Tavolaro, E. Drioli, Zeolite membranes, Adv. Mater. 11 (1999), 975

[4] X.B. Chen, W.S. Yang, L.W. Lin, Progress in the research of zeolite A membranes, Prog. Chem. 13 (2001) 392.

[5] J. Caro, M. Noack, Zeolite membranes - Recent developments and progress, Micropor.Mesopor.Mater.115 (2008) 215.

[6] X. Xua, W. Yang, J. Liu, L. Lin, N. Stroh, H. Brunner, Synthesis of NaA zeolite membrane on a ceramic hollow fiber, J. Membr. Sci..229 (2004) 81 .

[7] Y. Li, H. Chen, J. Liu, W. Yang, Microwave synthesis of LTA zeolite membranes without seeding, J. Membr. Sci..277 (2006) 230.

[8] N. Tijani, H. Ahlafi, M. El SMAIHI, a.elmansouri, Preparation and characterization of NaA Zeolite membranes and its application for removal of heavy metals Mediteranen journal of chemistry 2013, 2(3), 484-492

[9] M.D. Jia, B.S. Chen, R.D. Noble, J.L. Falconer, Ceramic-zeolite composite membranes and their application for separation of vapour gas mixtures, J. Membr. Sci. 90 (1994) 1.

[10] Z. Gao, Y. Yue and W. Li, Application of zeolitefilledpervaporation membrane, Zeolites, 16 (1996) 70.

[11] K. Aoki, K. Kusakabe, S. Morooka, Gas permeation properties of Atype zeolite membrane formed on porous substrate by hydrothermal synthesis, J. Membr. Sci. 141 (1998) 197.

[12] X. Chen1, W. Yang, J. Liu, L. Lin, Synthesis of zeolite NaA membranes with high permeance under microwave radiation on mesoporous-layer-modified macroporous substrates for gas separation, J. Membr. Sci. 255 (2005) 201.

[13] L.T.Y. Au, K.L. Yeung, An investigation of the relationship between microstructure and permeation properties of ZSM-5 membranes, J. Membr. Sci. 194 (2001) 33 - 55

[14] CHECKCELL program , Ed 2004, Jean Laugier et Bernard Bochu

[15] FULLPROF SUITE program, Ed 2012, J R Carvajal

[16] E. Mateo, M menendez, J. Coronas, N. Tijani, H. Ahlafi, L. Messaoudi, A. EL Gamouz, M. Ouammou preparation and characterisation of morrocan clay support for zeolitic membranes phychem news 442008 15-20 